\title{
Squalene: a multi-task link in the crossroads of cancer and aging
}

\author{
Alvaro L. Ronco ${ }^{1,2}$ and Eduardo De Stéfani ${ }^{3}$ \\ ${ }^{1}$ Department of Epidemiology and Scientific Methods, IUCLAEH School of Medicine, Prado \\ and Salt Lake p.16, Maldonado 20100, Uruguay; ${ }^{2}$ Unit of Oncology and Radiotherapy, \\ Pereira Rossell Women's Hospital, Bvar. Artigas 1550, Montevideo 11300, Uruguay; \\ ${ }^{3}$ Epidemiology Group, Department of Pathology, Clinicas Hospital, Av. Italia s/n, \\ Montevideo 11300, Uruguay
}

Correspondent author: Alvaro Ronco, MD, ${ }^{1}$ Department of Epidemiology and Scientific Methods, IUCLAEH School of Medicine, Prado and Salt Lake p.16, Maldonado 20100, Uruguay

Submission date: September 5, 2013; Acceptance date: December 14, 2013; Publication date: December 20, 2013

\begin{abstract}
Since its discovery in the beginning of the XXth century, squalene has been recognized as an important link in metabolic pathways. More recently, it has been further recognized as an intermediate step in the biosynthesis of cholesterol. Its well known antioxidant capability, together with its ability to protect skin, improve the immune system, and modulate the lipid profile, confer a high potential to this natural substance, which is spread all across the body structure, though mainly in the epithelial tissues, and in particular the skin sebum. This review will focus mainly on its major properties, which are related to anticancer properties, the maintenance of the oxidation/antioxidation balance, and its antiaging capabilities. Although the substance was originally obtained from shark liver oil, it is currently possible to obtain useful amounts from vegetable sources like extra virgin olive oil, therefore avoiding the dependence on capturing the aforementioned animal species. Recognized as one of the key components of the Mediterranean dietary style, squalene is necessary to adequately manage oxygen and its derivatives in every cell of the body.
\end{abstract}

Key words: aging, antioxidants, cancer, cholesterol, diet, olive oil, squalene

\section{Sources and structure}

Inhabitants of the Japanese Peninsula of Izu used to drink an oil that was locally named "Samedawa," which means "cure all". In 1916, Dr. Mitsumaru Tsujimoto, a Japanese industrial engineer, described ten years after his initial discovery that Samedawa contained extremely large quantities of an unsaturated hydrocarbon [1]. He named the hydrocarbon squalene, due to its presence in the liver oil of sharks, from the Latin root "squalus" (shark). 
Ten years later, its structure was established as a dihydrotriterpene, and the authors posited that it might be an intermediary in the biosynthesis of steroids [2].

In 1934, Robinson proposed a direct cyclization of squalene to the steroid molecule [3]. In 1936, Nobel laureate researcher Paul Karrer described the biochemical structure of squalene for the first time. He was already recognized for his discoveries on the chemical structures of Vitamins A and E [4].

The biochemical structure of squalene is $\mathrm{C}_{30} \mathrm{H}_{50}(\mathrm{C} 30: 6 \mathrm{n}-\Omega 2)$, a 30-carbon compound (polyprenyl, holding 6 prenyl groups, better known as isoprenoid or isoprene) (Figure 1).

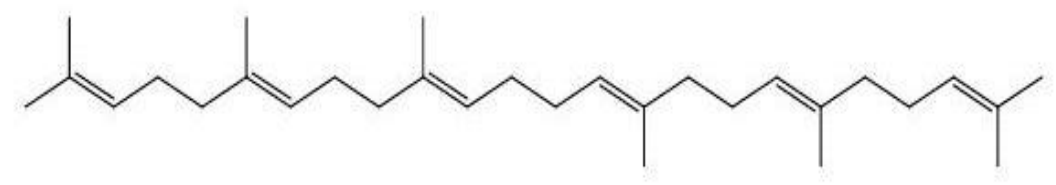

Figure 1. Chemical structure of squalene

Due to a double bond structure of six $\mathrm{CH}_{3}$ groups, the isoprenoid has a strong natural antioxidative effect. Squalene has a similar structure to other isoprenoids as $\beta$-carotene, lycopene, vitamin A, vitamin E, and coenzyme Q10 (ubiquinone) [5].

Until today, shark liver oil is considered the richest source of squalene, with squalene accounting for at least $40 \%$ of its weight. It is also widely distributed in nature, in lesser proportions in amaranth oil (6-9\%) [6], in wheat germ oil, and in olive oil (usually from $0.4 \%$ up to $1 \%$ in extra virgin olive oil) [7]. Evidence suggests that 60 to $80 \%$ of dietary squalene is absorbed from dietary intake [8,9]. Squalene was first found in the human body in the 1950's, when the metabolism of cholesterol was first identified [10]. Not long ago, knowledge spread that squalene is one of our body's own essential substances, which is present in small quantities in the skin and blood: the body synthesizes an average amount of $1.5 \mathrm{~g} /$ day [11]. Although the skin of primates has virtually no squalene, $12 \%$ of overall bodily squalene content in humans is in the sebum secreted by the skin. Furthermore, the daily secretion of squalene from the total skin surface ranges from 125 up to $475 \mathrm{mg} /$ day [12].

\section{Actions on the lipid profile: the best known history}

Squalene is an intermediate step in the biosynthesis of cholesterol and all steroid hormones. It is an inhibitor of the 3-hydroxy-3-methylglutaryl Coenzyme A (HMG-CoA) reductase activity and increases the activity of acyl CoA cholesterol acyltransferase [12]. In fact, the endogenous synthesis of squalene begins with the production of HMG-CoA. The initial reduction of HMG-CoA results in the formation of mevalonate [13]. Cholesterol is synthesized in a complex series of biochemical steps, known as the mevalonate pathway. After some biochemical reactions, featured by the addition of prenyl groups, the molecules of the intermediate group farnesyldiphosphate are gathered and reduced, resulting in the formation of squalene. After its biosynthesis, squalene can be transported to other regions of the body to be incorporated in tissues, or to be metabolized, resulting in the eventual synthesis of cholesterol and its steroid metabolites [14].

The presence of squalene in the cells affects the HMG-CoA reductase synthesis rate, which in turn affects the whole synthesis of isoprenoids and cholesterol. This offers possibilities for the prevention and treatment of high levels of "bad cholesterol," a risk factor for cardiovascular disease. However, "bad cholesterol" is not the only factor in 
cardiovascular disease risk: when "bad cholesterol" is attacked by free radicals, it becomes an even more harmful substance, oxidized cholesterol (oxLDL), which is known as the worst cholesterol [15].

\section{Squalene's workplace: the cell membranes}

Currently, squalene protects the cellular and the cytoplasmatic organoids' biomembranes from oxidative stress, as well contributing to maintaining order in the cholesterol metabolism and keeping harmful LDL-cholesterol at minimal levels [16]. Biomembranes are themselves highly vulnerable to the harm caused by free radicals, especially in the hydrophobic band between the two lipidic layers. Squalene is outstanding because of its great capability to receive or donate electrons without suffering a molecular alteration. Such stable and effective antioxidant configuration is given by its six isoprenoid units. Squalene can have two different forms: cyclic and noncyclic. The noncyclic form is entirely hydrophobic and is not engaged to the biological membrane. It is attracted by the band between both lipidic layers, the intermembrane. It accumulates there and performs its antioxidant task, capturing free radicals $[5]$.

Certain experimental models propose that hydrocarbons such as squalene, specifically located in the middle of the lipid bilayer, inhibit proton leaks, which are events that consume cellular energy in an unproductive way [17]. In particular, polyunsaturated fatty acids (including those in foods containing lipids) are prone to suffering from oxidation, and this plays an important role concerning the integrity of biological membrane. The capability of squalene to protect the linoleic, linolenic, docosahexaenoic, and eicosapentaenoic acids against temperature-dependent self-oxidation is outstanding [18].

A relevant point related to cholesterol synthesis and antioxidant actions is the cyclization of squalene to lanosterol, already described in the 50's [19], and dependent on the oxygen catchment by squalene [20] -in fact, it is oxydosqualene. Under certain given conditions, the noncyclic squalene loses its stability and curls itself, becoming cyclic and losing an important part of its antioxidant potential. It instead becomes the steroid nucleus. The molecules of cyclic squalene are known as hopanoids. It is not exactly known how this transformation takes place, but the noncyclical molecule enters into a cavity of a protein complex, it is divided into its six isoprenoids and then further reassembled into a new configuration. This is mandatory for being able to become the nucleus of cholesterol and other sterols [5].

In order to stabilize, squalene also attaches hydrogen ions from water and acids in the body, and in the process, releases oxygen to the body by the following reaction: $\mathrm{C}_{30} \mathrm{H}_{50}$ (squalene) $+6 \mathrm{H}_{2} \mathrm{O}$ (water) -> $\mathrm{C}_{30} \mathrm{H}_{62}$ (squalane) $+3 \mathrm{O}_{2}$ (oxygen) [20].

Squalene facilitates oxygen to reach the cellular level, causing further improvement in organ function through aerobic metabolism, which prevents acidotic cell syndrome, where cells become acidic, deteriorate, and die due to hypoxia [5].

\section{Actions as anticancer agent}

Extra virgin olive oil contains small amounts of bioactive substances, which usually do not exceed $2 \%$ of its weight. Nevertheless, in spite of their small amount, these substances have a large series of properties which are beneficial. Among them, the anticarcinogenic and antioxidant capabilities are outstanding. These minor components include polyphenols within a range of $100-500 \mathrm{mg} / \mathrm{kg}$ according to different authors [21]. The major part is formed by 
alcohols (tyrosol, hydroxytyrosol), but there are also other compounds such as flavonoids, lignans, and triterpenes. In regards to triterpenes, squalene is remarkable. A series of reviews have accepted that minor components of olive oil are potentially anticarcinogenic [22].

We recently performed a review of the relevant literature in Pubmed (5/July/2013) with the term "squalene" producing 3281 results, which have reached from the year 1926 up through 2013, most of which proceed from basic research. When the search added the term "cancer," results were restricted to 203, with the oldest one being from 1956, mainly involving studies linking squalene to the protection against skin cancer. Undoubtedly, the links between squalene and cancer are more recent than most of the previous studies, which relate this substance with cholesterol, steroid molecules, and cardiovascular and metabolic areas.

We have mentioned that squalene is chemically an isoprenoid, sharing that structure with carotenoids like lycopene, with vitamins $\mathrm{A}$ and $\mathrm{E}$, and also with other endogenous antioxidants as glutathione, superoxide dismutase, and ubiquinone (coenzyme Q10). All of these are powerful antioxidants. The previous paragraphs have remarked the extreme vulnerability of biomembranes to oxidative harm due to oxygen free radicals, especially in the hydrophobic band between the lipid bilayer. Squalene, usually located in this cellular zone, has an outstanding antioxidant capability recognized because of its highly stable structure. This capability is of major importance concerning the protective action against cancer (mainly thinking about reducing DNA damage), which has been remarked by the scientific literature.

The literature also recognizes in squalene an optimizing factor for the immune system. This has been observed in macrophages as well as in lymphocytes. Five decades ago, a published paper showed that squalene stimulates macrophages [23]. The evidence suggests that the biomembrane of immune cells is protected by squalene during phagocytosis, which makes them resistant to oxidative stress elements that such cells receive as an attack. The synthesis and consumption of squalene might be increased in those moments, like other antioxidants such as glutathione do. It has been found that two squalene precursors (geranyl and farnesyl) influence the synthesis and secretion of cytokines, which regulate the immune response. Interestingly, squalene precursors also regulate cellular growth and proliferation.

Ras is the most common family of oncogenes, found in $30 \%$ of cancers. Cancer cells activate the ras gene, which in turn synthesizes ras proteins and performs ras functions. The oncogenic ras protein is in a continuous activation state, leading to an uncontrolled cell division in the absence of growth signals [24]. The activation of these proteins depends on the isoprenoid metabolism in the neoplastic cells. Through isoprenylation, farnesylpyrophosphate fixes the ras protein to the cell membrane, and it also fixes some other important proteins to the cell membrane or to the nuclear cover. Without this vital step, the ras oncogene finds severe limitations for its activity [25]. Regarding the cell cycle, a G1 phase moving towards S phase requires two products of the mevalonate pathway for the protein isoprenylation: geranyl- and farnesylpyrophosphate [26,27]. Research results support the idea that inhibition of lipid metabolic pathways may be valuable as a possible molecular target for collaborating in the treatment of some cancers, e.g. lung [28], breast [29], esophagus [30], and sarcomas [31].

Farnesylpyrophosphate is of interest, because of its place in the isoprenoid synthesis pathway and its dependence on the HMG-CoA reductase. The presence of exogenous squalene establishes a negative feedback by inhibition of HMG-CoA reductase, then reducing 
the farnesylpyrophosphate synthesis, disrupting the synthesis of mevalonate pathway and inhibiting the protein isoprenylation. The latter is even more important in tumor cells than in normal ones, especially when the ras oncogene is hyperactivated [32]. As a consequence, its disruption is deleterious for the cancer cell. If squalene achieves a stop in the G1 phase of this cell, it prevents cellular growth and proliferation [5]. A daily intake of squalene can inhibit the isoprenoid production in neoplastic cells and present an obstacle for their growth and development. Some authors have found this to be a possible explanation for the anticancer properties of olive oil [25].

The presence of ROS (reactive oxygen species) is involved in several biological facts which typically take place in the initiation and progression of cancer, according to the hypothesis of persistent oxidative stress in cancer [33]: a) they can originate a persistent activation of transcription factors as Nuclear Factor kappa $\mathrm{B}(\mathrm{NF} \kappa \mathrm{B})$; b) they can induce the expression of proto-oncogenes such as c-fos, c-jun and c-myc; c) oxidative stress can result in tumor cells developing resistance to chemotherapy; d) reactive oxygen can damage certain proteins and enzymes, including protease inhibitors, probably facilitating tumor invasion and metastases.

Experimental research has shown a protective activity of olive oil against chemically induced carcinogenesis in the breast gland [34], colon [35], skin [36], and liver [37]. In particular, topical application of squalene showed anticarcinogenic activity [38,39]. Concerning the involved mechanisms, researchers have found that minor compounds have an impact on cell death and proliferation. Besides this, most nutrigenomic studies of olive oil were conducted in cancer research [40-44].

A dietary enrichment with the unsaponifiable fraction of olive oil reduces the damage of acute colitis, alleviating the oxidative events and returning the expression of proinflammatory proteins to basal levels, probably through inhibition of signaling pathways of p38, Mitogen-activated protein kinase (MAPK), Cyclo Oxygenase-2 (COX-2), Nitric oxide synthase (iNOS), NFkB, and by enhancement of the Peroxisome Proliferator-Activated Receptor-gamma (PPAR- $\gamma$ ) pathway $[45,46]$. Since this disease is a potential risk factor for colorectal cancer, the increase of unsaponifiable fraction could contribute to the prevention of such a tumor.

Two leading scientists in the field of nutrition and cancer, Theresa Smith and Harold Newmark, have suggested that the protective effect of extra virgin olive oil could be due to its squalene content $[8,25]$, a concept based on a considerable amount of experimental studies in animals. Most of these studies investigated the effect of squalene when topically applied or in a systemic way on chemically induced cancers of skin, colon, or lungs in rodents. Rao et al. supported Newmark's hypothesis, also suggesting that squalene, as a component of olive oil, could be partially responsible for the chemopreventive effect of the oil [47]. Considered together, these results clearly show that dietary squalene has different anticarcinogenic effects [38, 47-50].

In 1999, D.A. Hertzler et al. cited a review which [51] proposed that squalene had the potential to be part of a chemotherapy regimen for human pancreatic cancer.

Squalene is capable of inhibiting aberrant hyperproliferation, a cellular marker associated with preneoplastic transformation [52]. Other authors have investigated the effect of squalene on antitumoral activity and immune response of the host in female rodents bearing sarcoma 180. The intraperitoneal administration of squalene was seen to enhance the 
function of the reticuloendothelial system, in particular antibodies IgM, and a longer survival was observed in the animals [53].

The administration of squalene at $2 \%$ in the diet of rodents 14 days before and 30 days after a lethal total body irradiation with $\gamma$-rays, was followed by a cellular and systemic radioprotection. White blood cell count was consistently higher among the animals treated with squalene. This treatment was associated with a significant extension of survival time compared to the control group [54]. Beside this, the genotoxicity of doxorubicin has been reduced through administration of complementary squalene in rats [55]. The protection of bone marrow against the action of some antineoplastic drugs has been also documented [56]. Furthermore, this author's results suggest that squalene has a cytoprotective effect in vitro on pluripotential hematopoietic cells derived from bone marrow but does not protect cell lines of neuroblastoma from the toxicity induced by cisplatin [57]. According to this study, squalene would have a selective cytoprotective activity in normal cells against toxicity produced by chemotherapy, without protecting tumor cells.

Although the evidence supporting the use of squalene in combination with chemotherapy agents against cancer in humans is somehow reduced, such evidence suggests that squalene can potentiate the cytotoxic activity of some of those agents. The effect of squalene combined with ACNU (a nitrosourea) in a murine tumoral model, at doses of 4.2 $\mathrm{g} / \mathrm{kg}$ has shown capabilities of potentiating the effect of ACNU against lymphoid leukemia. The authors reported a longer survival of some animals, without toxicity [48]. Survival in cultured cell lines indicates that squalene also increased cytotoxicity and antitumoral activity of adriamicin, cyclophospamide, 5-fluoruracil, bleomicin, and cisplatin. The strongest potentiation effect was seen in bleomicin [58]. Basic research about squalene in breast cancer cell lines was recently carried out, emphasizing the increase in the cytotoxicity of adriamicin as well as an increase of antioxidant activity for normal cells [24]. Myelo- and nephrotoxicity due to agents like cisplatin and cyclophosphamide take place because of the generation of free radicals or because of the enhancement of oxidative metabolism. It is there that squalene is able to minimize certain tissue damages, in addition to potentiating cytotoxicity in cancerous cells [59]. We can recognize, therefore, that there seem to be significant powerful antioxidant and cytoprotective effects in squalene.

The convenience of combining the nutritional-pharmacologic effects in which squalene participates had already been suggested some years ago [60], regarding a combination of olive oil together with sulindac (as a COX-2 inhibitor), which represents an advantage considering the practical feasibility of this combination.

In a recent publication on nutrition and breast cancer [61], we have emphasized the potentially high usefulness of squalene as supplement with a double purpose: On one hand, collaborating with a nutritional style for the prevention of the disease; on the other hand, collaborating with different oncospecific therapies that patients must usually receive.

From surgery through radiotherapy and also chemotherapy, there is a space for coadjuvance with squalene in the treatment. Tumor cells live better in environments reached by small amount of oxygen (anaerobic ones), and oxygenation is harmful for them: this is obviously well known by specialists. A sustained acidosis is a potential upstream and indirect trigger in a multifactorial cascade of molecular events associated with carcinogenesis. The extracellular space of most tumors is mildly acidic, due to an exuberant production of lactic acid. There is growing evidence that extracellular acidity per se boosts the invasiveness and metastatic capacity of cancer cells [62]; moreover, this acidity renders cancer cells relatively 
resistant to the high proportion of chemotherapeutic drugs that are mildly basic, and may impede immune rejection of tumors [63]. If the whole body is better oxygenated, the cytotoxicity of radio- and chemotherapy on malignant cells will be enhanced, and the oxygen will contribute to the protection of healthy cells (which are the majority). The quoted ability of squalene to neutralize a proton excess derived from metabolism could be somehow associated to the alkalizing action of fruits and vegetables, which has scientific support [64].

Squalene appears to have twice the capability of wiping the harmful oxygen and distributing the useful oxygen. Hence, there is an opportunity to profit from such potentiality without the risks of a pharmaceutical drug.

As an adjuvant therapy for cancer in humans, the information about the optimal doses is not available either. Anyway, if liver steatosis emerges as a consequence of some state-ofthe-art cancer therapy, squalene appears as a helpful tool with the ability to normalize the situation, since it contributes to hepatic detoxification. Some experimental researchers have reported that animals fed with squalene show an enhanced capacity to excrete toxins such as hexachlorobenzene or strychnine [65-67]. Squalene can attract xenobiotic products which are highly lipophilic, contributing then to their body elimination [68]. As an extrapolation from available animal data, a dose between 2-5 g/day seems to be the therapeutic window. The experience in the therapy of chronic lead toxicity in Uruguayan children has been very useful [69], profiting from the high detoxifying capability of squalene. The researchers employed doses up to $6.5 \mathrm{~g} /$ day without any signs of toxicity or intolerance. The aforementioned experience without adverse side effects could be useful as a reference for its clinical administration, also taking into account the different ratio dose $(\mathrm{g}) / \mathrm{body}$ weight $(\mathrm{kg})$ in children.

In conclusion, we could say that the epidemiological, experimental and clinical evidence about the anticancer properties of squalene are promising. This substance could have a place as an adjuvant together with specific oncologic therapies. Furthermore, in the light of the existing evidence, we do not find any strong arguments against the intake of squalene among cancer patients within a range of 2-6 g/day.

\section{Actions as an antiaging agent}

According to the World Health Organization, aging, or senescence, is "the series of morphologic and physiologic changes which appear as a consequence of the action of time on living beings, which supposes a reduction of adaptive capabilities in each one of the organs and systems, as well as in the capability of response to harmful agents with incidence in the individual" [70].

Aging is a complex process which is expressed in an organism at several levels: genetic, molecular, cellular, in organs, and in systems. Albeit, the fundamental mechanisms are still not well known, there is increasing evidence pointing to the "reactive species" of oxygen and nitrogen, as one of the primary determinants of aging. The theory of oxidative stress states that a progressive and irreversible accumulation of oxidative damage caused by reactive species impacts critical aspects of the aging process, contributing to damaged physiological functions, a higher incidence of diseases, and a reduction in life extension [71].

Research has generated very strong data which supports the theory of oxidative stress. Nevertheless, a direct cause-effect relationship between the accumulation of damage due to oxidation and aging has not been clearly established [72]. The oxidative damage of cellular and tissular components is located among the primary or secondary factors in the aging 
process as well as in different human diseases (e.g. cardiovascular, cancer, diabetes, neuromuscular disfunctions, and degenerative processes) [73].

Oxidative stress refers to a serious imbalance between the production of reactive species and antioxidant defenses. The degree of stress is determined by the quoted balance or imbalance level. Regardless of how or where reactive species are generated, an increase of intracellular concentrations of oxidants has two important and potential effects: a) several cellular components are damaged [74,75]; and b) the activation of specific signaling pathways is triggered [74-76].

Both effects can influence numerous cellular processes related to aging and the development of diseases related to age. Oxidative stress status is under a strong regulatory control for most people, based on a wide range of lifestyle variables, which include diet and physical activity.

It has been shown that a high level of oxidative stress in humans could be reduced to a normal level through antioxidant supplements [73]. This fact has clinical implications but also gives another important message: a daily dietary which is simply rich in natural antioxidants could prevent and defend our organism against the incidence of diseases which are age-associated.

A Mediterranean-type diet was already observed in the 90's as good for human health, reducing the incidence of coronary diseases [77] and certain types of cancer [78]. Because of its abundant foods which were rich in vitamins, antioxidants, and monounsaturated fatty acids -all of them being potentially active in the protection against diseases associated to age--the Mediterranean diet was recognized as a "functional diet" which protects human health [79,80]. Experimental studies carried out in the past decade in human volunteers [81-84] showed that some of the minor components of olive oil (polyphenols, squalene) contributed significantly towards its benefits on health. After a meal rich in fats, an oxidative stress takes places and triggers inflammation, endothelial disfunction, hypercoagulability, and a cascade of other atherogenic changes [85]. However, the intake of fatty foods with adequate sources of antioxidants, like a Mediterranean-type meal, can minimize the postprandial oxidative stress [86].

In this review we have already mentioned that squalene works as a powerful scavenger of oxygen free radicals, hence inhibiting the lipoperoxidation induced e.g. by UV radiations [87]. Besides this, its capability for the inhibition of HMG-CoA reductase stops cholesterol biosynthesis while it facilitates its excretion through bile [88]. In addition, squalene generates a modulation on the action of immune system on the arteries, something fundamental in order to stop atherogenesis $[89,90]$. This has also been recognized for other minor components of olive oil [91,92]. The arterial protection determined by these facts, together with the recognized antioxidant capability of dietary squalene, somehow represents an antiaging action, since arterial age is closely associated to its level of atherosclerosis. Aging makes the maintenance of the oxidation/antioxidation balance even more difficult, because the body's own antioxidant synthesis -in the same way the one of other important nutrients- declines with the advance of age.

It is interesting to remark that the interventions with components rich in antioxidants at dietary doses in healthy volunteers exert only marginal effects. In addition, detecting those effects could be difficult due to the current status of oxidative biomarkers [93]. In fact, the protective effect of minor components of olive oil on the oxidative damage in humans was better displayed in participants with a compromised oxidative status (men having a low- 
antioxidant diet, postmenopausal women) or in patients with a high status of oxidative stress (hyperlipidemic, coronary disease, hypercholesterolemic, etc).

The same facts were observed by us in epidemiological studies related to nutrition and cancer $[94,95]$. For example, the increase of intake of $\Omega-3$ fatty acids through diet as well as through supplementation (and the same in the case of vegetables and fruits intake) suggest that there would not be a protective effect (or perhaps it might be strongly reduced) among those who have higher intake of them. On the contrary, when their negative risk association (protective effect) was stronger, the higher was the deficit prior to diagnosis. Observations suggest that when the oxidant/antioxidant status is adequate, it cannot be significantly improved by the addition of antioxidant foods. Conversely, the potentially beneficial effect of the latter is higher, as higher is the previous imbalance (oxidative stress).

Olive oil, as the complex food it is, can have a series of direct and indirect effects on genetic expression. The direct effect is the interaction with a series of transcription factors which are responsible for the positive-negative regulation of genic expression. The indirect effects refer to the interaction related to the metabolism on the cascades of cellular signaling which modify the genic transcription [96-98]. Several genes have been identified in experimental animal models as responders to the intake of olive oil [99].

\section{Concluding remarks}

Squalene, an unsaturated compound, appears to contribute to the formation of useful oxygen when combined with water, and also to the efficient transportation of that useful oxygen to the whole body, helping in that way to maximize the catchment of such element. Having that capability, the likelihood of generating underoxygenated microenvironments which produce metabolic acidosis using anaerobic metabolism is reduced. The main problem derived from those anaerobic environments is that they facilitate the development of degenerative pathologies and cancer, among other alterations. These concepts are equivalent to saying that an adequate intake of squalene is preventive of cell aging, since it adequately maintains the nutritional levels of the requested oxygen.

The present review intended to briefly outline and discuss some important roles that squalene plays in the human body. It can be distinguished by the common property of antioxidant and oxygen administrator and it could be considered as a biological response modifier, regarding oxygen, the immune system and steroid synthesis. The impact on oxygen behavior also determines a control on inflammation processes, tightly linked to the development of several prevalent chronic diseases as cancer. If all these were not even considered enough to accept squalene as an outstanding substance, its detoxifying capability against xenobiotic products is another advantage as regards its performance. In view of the high concentration differences of squalene between shark liver oil $(\geq 60 \%)$ and olive oil $(\leq 1 \%)$, and also taking into account the ecological impact of capturing marine species, it would be desirable to have higher squalene concentrations in vegetable sources like olive oil (in which it is also enhanced by the action of other minor components), as an eco-friendly alternative.

According to the scientific literature and to our knowledge, no specific medical syndrome due to squalene deficiency has been described. In the opinion of the authors, this fact does not preclude us to think of squalene as essential for life and, furthermore, to consider it a must of healthy nutrition in modern times. 
List of abbreviations: ACNU: amino methyl nitrosourea hydrochloride; COX : cyclooxygenase; HMG-CoA : 3-hydroxy-3-methylglutaryl Coenzyme A; iNOS : nitric oxide synthase; LDL : low-density lipoprotein; MAPK : mitogen-activated protein kinase; PPAR- $\gamma$ : peroxisome proliferator-activated receptor-gamma

\section{Authors' contributions}

A.L.R. designed the manuscript, performed the bibliographic research and wrote most of the text. E.D.S. made technical suggestions and reviews of the text.

\section{Acknowledgments}

The authors wish to thank Dr. Magdalena De Stéfani for her technical review on the English style and grammar of the present paper.

\section{REFERENCES}

1. Tsujimoto M: A highly unsaturated hydrocarbon in shark liver oil. J Ind Eng Chem 1916, 8(10):889-896.

2. Heilbron IM, Kamm ED, Owens WM: The unsaponifiable matter from the oils of elasmobranch fish. Part I. A contribution to the study of the constitution of squalene (spinacene). J Chem Soc 1926, 1630-1644.

3. Robinson R: Structure of cholesterol. J Soc Chem Ind 1934, 53:1062.

4. Karrer P: Lehrbuch der Organischen Chemie. G.Thieme Verlag, Leipzig, $9^{\text {th }}$ ed. 1943.

5. Das B: The science behind Squalene (The Human Antioxidant). ICBR Publishers, Toronto, 2000.

6. Martirosyan DM, Miroshnichenko LA, Kulakova SN, Pogojeva AV, Zoloedov VI: Amaranth oil application for coronary heart disease and hypertension. Lipids Health Dis 2007, 6:1

7. Owen RW, Mier W, Giacosa A, Hull WE, Spiegelhalder B, Bartsch H: Phenolic compounds and squalene in olive oils: the concentration and antioxidant potential of total phenols, simple phenols, secoiridoids, lignans and squalene. Food Chem Toxicol 2000; 38:647-659.

8. Smith TJ: Squalene: potential chemopreventive agent. Expert Opin Investig Drugs 2000, 9:1841-1848.

9. Kelly GS; Squalene and its potential clinical use. Altern Med Rev 1999, 4(1):2936.

10. MacKenna RMB, Wheatley VR, Wormall A: The composition of surface skin fat (sebum) from the human forearm. J Invest Dermatol 1950, 15:33-47.

11. Liu GC, Ahrens EH, Schreibman PH, Crouse JR: Measurement of squalene in human tissues and plasma: validation and application. J Lipid Res 1976, 17:38-45.

12. Langdon RG, Bloch K: The utilization of squalene in the biosynthesis of cholesterol. J Biol Chem 1953, 200(1):135-144.

13. Ačimovič J, Rozman D: Steroidal triterpenes of cholesterol synthesis. Molecules 2013, 18(4): 4002-4017.

14. Navarro V, Zabala A, Gómez S, Portillo M: Metabolismo del colesterol: bases actualizadas. Rev Esp Obes 2009, 7(6): 360-384.

15. Sharpe LJ, Brown AJ: Controlling cholesterol synthesis beyond 3-hydroxy-3-methylglutarylCoA reductase (HMGCR). J Biol Chem 2013, 288(26):18707-18715.

16. Goldstein JL, Brown MS: Progress in understanding the LDL receptor and HMG-CoA reductase, two membrane proteins that regulate the plasma cholesterol. J Lipid Res 1984, 25:1450-1461.

17. Hauß T, Dante S, Dencher NA, Haines TH: Squalane is in the midplane of the lipid bilayer: implications for its function as a proton permeability barrier. Biochim Biophys Acta 2002, 1556(2-3):149-154. 
18. Dessi MA, Deiana M, Day BW, Rosa A, Banni S, Corongiu FP: Oxidative stability of polyunsaturated fatty acids: effect of squalene. Eur J Lipid Sci Tech 2002; 104(8): 506-512.

19. Woodward RB, Bloch K: The cyclization of squalene in cholesterol synthesis. J Am Chem Soc 1953, 75:2023.

20. Tchen TT, Bloch K: On the conversion of squalene to lanosterol in vitro. J Biol Chem 1957, 226 (2): 921-930.

21. Christian M: Final report on the safety assessment of squalane and squalene. J Am Coll Toxicol 1982, 1 (2): 37-56.

22. Murkovic M, Lechner S, Pietzka A, Bratacos M, Katzogiannos E: Analysis of minor components in olive oil. J Biochem Biophys Methods 2004, 61 (1-2): 155-60.

23. Sotiroudis TG, Kyrtopoulos SA: Anticarcinogenic compounds of olive oil and related biomarkers. Eur J Nutr 2008, 47 Suppl 2:69-72.

24. Heller JH, Pasternak VZ, Ranson JP, Heller MS: A new reticulo-endothelial stimulating agent from shark livers. Nature (London) 1963, 199:904-905.

25. Warleta F, Ruiz-Mora J, Campos-Segura M, Serrano MJ, Gaforio JJ: El escualeno, componente minoritario del aceite de oliva, y su relación con el cáncer. Aceite de Oliva y Salud, I Congreso de Cultura del Olivo 2007, 765-782. ISBN 978-84-96047-57-0.

26. Newmark HL: Squalene, olive oil, and cancer risk. Review and Hypothesis. In: Cancer Prevention. Novel nutrient and pharmaceutical developments. Ann NY Acad Sci 1999, 889:193-203.

27. Brown MS, Goldstein JL: Multivalent feedback regulation of HMG CoA reductase, a control mechanism coordinating isoprenoid synthesis and cell growth. J Lipid Res 1980, 21(5):505517.

28. Maltese WA, Sheridan KM: Isoprenoid synthesis during the cell cycle. Studies of 3-hydroxy3-methylglutaryl-coenzyme A synthase and reductase and isoprenoid labeling in cells synchronized by centrifugal elutriation. J Biol Chem 1988, 263(21):10104-10110.

29. Yano K: Lipid metabolic pathways as lung cancer therapeutic targets: a computational study. Int J Mol Med 2012, 29(4):519-529.

30. Ginestier C, Monville F, Wicinski J, Cabaud O, Cervera N, Josselin E, Finetti P, Guille A, Larderet G, Viens P, Sebti S, Bertucci F, Birnbaum D, Charafe-Jauffret E. Mevalonate metabolism regulates Basal breast cancer stem cells and is a potential therapeutic target. Stem Cells 2012, 30(7):1327-1337.

31. Shi J, Zhu J, Zhao H, Zhong C, Xu Z, Yao F: Mevalonate pathway is a therapeutic target in esophageal squamous cell carcinoma. Tumour Biol 2013, 34(1):429-435.

32. Nilsson S, Huelsenbeck J, Fritz G: Mevalonate pathway inhibitors affect anticancer druginduced cell death and DNA damage response of human sarcoma cells. Cancer Lett 2011, 304(1):60-69.

33. Khosravi-Far R, Cox AD, Kato K, Der CJ: Protein prenylation: key to ras function and cancer intervention? Cell Growth Differ 1992, 3(7):461-469.

34. Toyokuni S, Okamoto K, Yodoi J, Hiai H: Persistent oxidative stress in cancer. FEBS Letters 1995, 358:1-3.

35. Lasekan JB, Clayton MK, Gendron-Fitzpatrick A, Ney DM: Dietary olive and safflower oils in promotion of DMBA-induced mammary tumorigenesis in rats. Nutr Cancer 1990, 13:153163.

36. Bartoli R, Fernández-Bañares F, Navarro E, Castellá E, Mañé J, Álvarez M, Pastor C, Cabré E, Gassull MA: Effect of olive oil on early and late events of colon carcinogenesis in rats: modulation of arachidonic acid metabolism and local prostaglandin E(2) synthesis. Gut 2000, 46:191-199.

37. Ichihashi M, Ahmed NU, Budiyanto A, Wu A, Bito T, Ueda M, Osawa T : Preventive effect of antioxidant on ultraviolet-induced skin cancer in mice. J Dermatol Sci 2000, 23:S45-S50. 
38. Thuy NT, He P, Takeuchi H: Comparative effect of dietary olive, safflower, and linseed oils on spontaneous liver tumorigenesis in C3H/He mice. J Nutr Sci Vitaminol (Tokyo) 2001, 47:363-366.

39. Van Duuren BL, Goldschmidt BM: Co-carcinogenic and tumor-promoting agents in tobacco carcinogenesis. J Natl Cancer Inst 1976, 56:1237-1242.

40. Murakoshi M, Nishino H, Tokuda H, Iwashima A, Okuzumi J, Kitano H, Iwasaki R: Inhibition by squalene of the tumor-promoting activity of 12-O-tetradecanoylphorbol-13acetate in mouse-skin carcinogenesis. Int J Cancer 1992, 52: 950-952.

41. Escrich E, Moral R, Grau L, Costa I, Solanas M: Molecular mechanisms of the effects of olive oil and other dietary lipids on cancer. Mol Nutr Food Res 2007, 51(10):1279-1292.

42. Escrich E, Solanas M, Moral R, Costa I, Grau L: Are the olive oil and other dietary lipids related to cancer? Experimental evidence. Clin Transl Oncol 2006, 8(12):868-883.

43. Menendez JA, Lupu R: Mediterranean dietary traditions for the molecular treatment of human cancer: anti-oncogenic actions of the main olive oil's monounsaturated fatty acid oleic acid (18:1n-9). Curr Pharm Biotechnol 2006, 7(6):495-502.

44. Menendez JA, Vazquez-Martin A, Oliveras-Ferraros C, García-Villalba R, CarrascoPancorbo A, Fernández-Gutiérrez A, Segura-Carretero A: Analyzing effects of extra-virgin olive oil polyphenols on breast cancer-associated fatty acid synthase protein expression using reverse-phase protein microarrays. Int J Mol Med 2008, 22(4):433-439.

45. Menendez JA, Vazquez-Martin A, Oliveras-Ferraros C, García-Villalba R, CarrascoPancorbo A, Fernández-Gutiérrez A, Segura-Carretero A: Extra-virgin olive oil polyphenols inhibit HER2 (erbB-2)-induced malignant transformation in human breast epithelial cells: relationship between the chemical structures of extra-virgin olive oil secoiridoids and lignans and their inhibitory activities on the tyrosine kinase activity of HER2. Int J Oncol 2009, 34(1):43-51.

46. Sánchez-Fidalgo S, Cárdeno A, Sánchez-Hidalgo M, Aparicio-Soto M, Villegas I, Rosillo MA, Alarcón de la Lastra C: Dietary unsaponifiable fraction from extra virgin olive oil supplementation attenuates acute ulcerative colitis in mice. Eur J Pharm Sci 2012, 48(3): 572581.

47. Sánchez-Fidalgo S, Cárdeno A, Sánchez-Hidalgo M, Aparicio-Soto M, Alarcón de la Lastra C: Dietary extra virgin olive oil polyphenols supplementation modulates DSS-induced chronic colitis in mice. J Nutr Biochem 2013, 24(7): 1401-1413.

48. Rao CV, Newmark HL, Reddy BS: Chemopreventive effect of squalene on colon cancer. Carcinogenesis 1998, 19:287-290.

49. Yamaguchi T, Nakagawa M, Hidaka K, Yoshida T, Akiyama S, Kuwano M: Potentiation by squalene of antitumor effect of 3-[(4-amino-2-methyl-5-pyrimidinyl) methyl]-1-(2chloroethyl)-nitrosourea in a murine tumor system. Jpn J Cancer Res 1985, 76:1021-1026.

50. Smith TJ, Yang GY, Seril DN, Liao J, Kim S: Inhibition of 4-(methylnitrosamino)-1-(3pyridyl)-1-butanone-induced lung tumorigenesis by dietary olive oil and squalene. Carcinogenesis 1998, 19:703-706.

51. Smith TJ, Kim S, Lee MJ, Yang GY, Newmark HL, Yang CS: Inhibition of 4(methylnitrosamino)-1-(3-pyridyl)-1-butanone (NKK)-induced lung tumorigenesis and DNA oxidation by dietary squalene. Proc Am Assoc Cancer Res 1999, 40: 262.

52. Gapor MT, Hazrina AR: Squalene in oils and fats. Palm Oil Developments 2000, 32: 36-40. Katdare M, Singhal H, Newmark H, Osborne MP, Telang NT: Prevention of mammary preneoplastic transformation by naturally-occurring tumor inhibitors. Cancer Lett 1997, 111:141-147.

53. Ohkuma T, Otagiri K, Tanaka S, Ikekawa T: Intensification of host's immunity by squalene in sarcoma 180 bearing ICR mice. J Pharmacobiodyn 1983, 6:148-151. 
54. Storm HM, Oh SY, Kimler BF, Norton S: Radioprotection of mice by dietary squalene. Lipids 1993, 28:555-559.

55. Narayan BH, Tatewaki N, Giridharan VV, Nishida H, Konishi T: Modulation of doxorubicininduced genotoxicity by squalene in Balb/c mice. Food Funct 2010, 1(2):174-179.

56. Das B, Antoon R, Tsuchida R, Lotfi S, Morozova O, Farhat W, Malkin D, Koren G, Yeger $\mathrm{H}$, Baruchel S: Squalene selectively protects mouse bone marrow progenitors against cisplatin and carboplatin-induced cytotoxicity in vivo without protecting tumor growth. Neoplasia 2008, 10(10):1105-1119.

57. Das B, Yeger H, Baruchel H, Freedman MH, Koren G, Baruchel S: In vitro cytoprotective activity of squalene on a bone marrow versus neuroblastoma model of cisplatin-induced toxicity: implications in cancer chemotherapy. Eur J Cancer 2003, 39:2556-2565.

58. Nakagawa M, Yamaguchi T, Fukawa H, Ogata J, Komiyama S, Akiyama S, Kuwano M: Potentiation by squalene of the cytoxicity of anticancer agents against cultured mammalian cells and murine tumor. Jpn J Cancer Res 1985, 76:315-320.

59. Desai KN, Wei H, Lamartiniere CA: The preventive and therapeutic potential of squalene containing compounds on tumour promotion and regression. Cancer Lett 1996, 101:93-96.

60. Schwartz B, Birk Y, Raz A, Madar Z: Nutritional-pharmacological combinations--a novel approach to reducing colon cancer incidence. Eur J Nutr 2004, 43(4):221-229.

61. Ronco AL, De Stéfani E (eds): Nutritional Epidemiology of Breast Cancer. $1^{\text {st }}$ Ed, Springer Publishers, Dordrecht 2012.

62. Calorini L, Peppicelli S, Bianchini F: Extracellular acidity as favouring factor of tumor progression and metastatic dissemination. Exp Oncol 2012, 34(2):79-84.

63. McCarty MF, Whitaker J: Manipulating tumor acidification as a cancer treatment strategy. Altern Med Rev 2010, 15(3):264-272.

64. Robey IF: Examining the relationship between diet-induced acidosis and cancer. Nutrition \& Metabolism 2012, 9:72.

65. Richter E, Fichtl B, Schafer SG: Effects of dietary paraffin, squalane and sucrose polyester on residue disposition and elimination of hexachlorobenzene in rats. Chem Biol Interact 1982, 40:335-344.

66. Richter E, Schafer SG: Effect of squalane on hexachlorobenzene (HCB) concentrations in tissues of mice. J Environ Sci Health B 1982, 17:195-203.

67. Kamimura H, Koga N, Oguri K, Yoshimura H: Enhanced elimination of theophylline, phenobarbital and strychnine from the bodies of rats and mice by squalane treatment. $\mathrm{J}$ Pharmacobiodyn 1992, 15:215-221.

68. Kalogeropoulos N, Chiou A, Gavala E, Christea M, Andrikopoulos NK: Nutritional evaluation and bioactive microconstituents (carotenoids, tocopherols,sterols and squalene) of raw and roasted chicken fed on DHA-rich microalgae. Food Res Int 2010; 43: 2006-13.

69. Queirolo E, Morales MG, Iacopino A: Tratamiento con Semo-Squalene en la intoxicación crónica por plomo en niños. XV Congreso Argentino de Toxicología, Neuquén, Argentina. Acta Toxicol Argentina 2007, [Abstract] P78:p53.

70. World Health Organization: http://www.who.int/topics/ageing/es/ [Accessed 05-06-2013]

71. Sohal RS, Orr WC: The redox hypothesis of aging. Free Radic Biol Med 2012, 52(3):539555.

72. Kregel KC, Zhang HJ: An integrated view of oxidative stress in aging: basic mechanisms, functional effects, and pathological considerations. Am J Physiol Regul Integr Comp Physiol 2007, 292(1):R18-36.

73. Cutler RG: Oxidative stress profiling: part I. Its potential importance in the optimization of human health. Ann N Y Acad Sci 2005, 1055:93-135.

74. Finkel T, Holbrook NJ: Oxidants, oxidative stress and the biology of ageing. Nature 2000, 408(6809):239-247. 
75. Valko M, Leibfritz D, Moncol J, Cronin MTD, Mazur M, Telser J: Free radicals and antioxidants in normal physiological functions and human disease. Int J Biochem Cell Biol 2007, 39(1):44-84.

76. Owuor ED, Kong AN: Antioxidants and oxidants regulated signal transduction pathways. Biochem Pharmacol 2002, 64(5-6):765-770.

77. Katan MB, Zock PL, Mensink RP: Dietary oils, serum lipoproteins, and coronary heart disease. Am J Clin Nutr 1995, 61:1368S-1373S.

78. Willett WC, Sacks F, Trichopoulou A, Drescher G, Ferro-Luzzi A, Helsing E, Trichopoulos D: Mediterranean diet pyramid: a cultural model for healthy eating. Am J Clin Nutr 1995, 61 (Suppl.6):1402S-1406S.

79. Ortega RM: Importance of functional foods in the Mediterranean diet. Public Health Nutr 2006, 9 (8A):1136-1140.

80. López-Miranda J, Pérez-Jiménez F, Ros E, De Caterina R, Badimón L, Covas MI, Escrich E, Ordovás JM, Soriguer F, Abiá R, Alarcón de la Lastra C, Battino M, Corella D, ChamorroQuirós J, Delgado-Lista J, Giugliano D, Esposito K, Estruch R, Fernández-Real JM, Gaforio JJ, La Vecchia C, Lairon D, López-Segura F, Mata P, Menéndez JA, Muriana FJ, Osada, Panagiotakos DB, Paniagua JA, Pérez-Martínez P, Perona J, Peinado MA, Pineda-Priego M, Poulsen HE, Quiles JL, Ramírez-Tortosa MC, Ruano J, Serra-Majem L, Solá R, Solanas M, Solfrizzi V, de la Torre-Fornell R, Trichopoulou A, Uceda M, Villalba-Montoro JM, VillarOrtiz JR, Visioli F, Yiannakouris N: Olive oil and health: summary of the II international conference on olive oil and health consensus report, Jaén and Córdoba (Spain) 2008. Nutr Metab Cardiovasc Dis 2010, 20(4):284-294.

81. Fitó M, Gimeno E, Covas MI, Miró E, López-Sabater M, Farré M, de la Torre R, Marrugat J: Postprandial and short-term effects of dietary virgin olive oil on oxidant/antioxidant status. Lipids 2002, 37(3):245-251.

82. Fitó M, Cladellas M, de la Torre R, Martí J, Alcántara M, Pujadas-Bastardes M, Marrugat J, Bruguera J, López-Sabater MC, Vila J, Covas MI: Antioxidant effect of virgin olive oil in patients with stable coronary heart disease: a randomized, crossover, controlled, clinical trial. Atherosclerosis 2005, 181(1):149-158.

83. Marrugat J, Covas MI, Fitó M, Schröder H, Miró-Casas E, Gimeno E, López-Sabater MC, de la Torre F, Farré M: Effects of differing phenolic content in dietary olive oils on lipids and LDL oxidation--a randomized controlled trial. Eur J Nutr 2004, 43(3):140-147.

84. Weinbrenner T, Fitó M, de la Torre R, Sáez GT, Rijken P, Tormos C, Coolen S, Farré M, Abanades S, Schröder H, Marrugat J, Covas MI: Olive oils high in phenolic compounds modulate oxidative/ antioxidative status in men. J Nutr 2004, 134(9):2314-2321.

85. O'Keefe JH, Bell DS: Postprandial hyperglycemia/hyperlipidemia (postprandial dysmetabolism) is a cardiovascular risk factor. Am J Cardiol 2007, 100(5):899-904.

86. Sies H, Stahl W, Sevanian A: Nutritional, dietary and postprandial oxidative stress. J Nutr 2005, 135(5):969-972.

87. Dennis K, Shimamoto T: Production of malonyldialdehyde from squalene, a major skin surface lipid, during UV irradiation. Photochem Photobiol 1989, 49; 711-719.

88. Strandberg TE, Tilvis RS, Miettinen TA: Metabolic variables of cholesterol during squalene feeding in humans: comparison with cholestyramine treatment. J Lipid Res 1990, 31:16371643.

89. Granados-Principal S, Quiles JL, Ramirez-Tortosa CL, Ochoa-Herrera J, Pérez-López P, Pulido-Moran M, Ramírez-Tortosa MC: Squalene ameliorates atherosclerotic lesions through the reduction of CD36 scavenger receptor expression in macrophages. Mol Nutr Food Res 2012, 56(5):733-740. 
90. Cabello-Moruno R, Perona JS, Ruiz-Gutierrez V: Influence of minor components of olive oils on the composition and size of TRLs and on macrophage receptors involved in foam cell formation. Biochem Soc Trans 2007, 35(Pt 3):470-471.

91. Lou-Bonafonte JM, Arnal C, Navarro MA, Osada J: Efficacy of bioactive compounds from extra virgin olive oil to modulate atherosclerosis development. Mol Nutr Food Res 2012, 56(7):1043-1057.

92. Graham VS, Lawson C, Wheeler-Jones CP, Perona JS, Ruiz-Gutiérrez V, Botham KM: Triacylglycerol-rich lipoproteins derived from healthy donors fed different olive oils modulate cytokine secretion and cyclooxygenase- 2 expression in macrophages: the potential role of oleanolic acid. Eur J Nutr 2012, 51(3):301-309.

93. Giustarini D, Dalle-Donne I, Tsikas D, Rossi R: Oxidative stress and human diseases: Origin, link, measurement, mechanisms, and biomarkers. Crit Rev Clin Lab Sci 2009, 46(5-6):241281.

94. De Stéfani E, Deneo-Pellegrini H, Boffetta P, Ronco AL, Aune D, Acosta G, Mendilaharsu M, Brennan P, Ferro G: Dietary Patterns and Risk of Cancer: A Factor Analysis in Uruguay. Int J Cancer 2009, 124(6):1391-1397.

95. De Stéfani E, Ronco AL, Boffetta P, Deneo-Pellegrini H, Correa P, Acosta G, Mendilaharsu M: Nutrient-derived dietary patterns and risk of colorectal cancer: a factor analysis in Uruguay. Asian Pac J Cancer Prev 2012, 13(1):231-235.

96. Roche HM: Dietary lipids and gene expression. Biochem Soc Trans 2004, 32(Pt 6):999-1002.

97. Müller M, Kersten S: Nutrigenomics: goals and strategies. Nat Rev Genet 2003, 4(4):315322.

98. Santangelo C, Varì R, Scazzocchio B, Di Benedetto R, Filesi C, Masella R: Polyphenols, intracellular signalling and inflammation. Ann Ist Super Sanita 2007, 43(4):394-405.

99. Guillén N, Acín S, Navarro MA, Surra JC, Amal C, Lou-Bonafonte JM, Muniesa P, MartínezGracia MV, Osada J: Knowledge of the biological actions of extra virgin olive oil gained from mice lacking apolipoprotein E. Rev Esp Cardiol 2009, 62(3):294-304. 